Check for updates

London

Cite this as: BMJ 2021;374:n1749 http://dx.doi.org/10.1136/bmj.n1749 Published: 08 July 2021

\title{
Covid-19: Failings in imaging services have put cancer patients at risk, watchdog says
}

Shaun Griffin

The government should urgently prioritise improving NHS imaging services in England, which are too often failing to detect cancer in scans and radiography, the Parliamentary and Health Service Ombudsman service has recommended.

The watchdog body has written letters to the patient safety minister, Nadine Dorries, and others to highlight findings from its report, published this week, ${ }^{1}$ that show recurring failings in the way $\mathrm{x}$ ray and scan results are reported on and followed up across the NHS. Rapid improvements in diagnosis will be crucial to tackle the backlog of care caused by the covid-19 pandemic, it said.

The ombudsman, Rob Behrens, said, " $X$ ray and scan results are key to diagnosis and treatment for many people. Yet the failings outlined in this report show that, without a concerted effort to improve imaging, patient safety continues to be at risk.”

The ombudsman's team analysed 25 complaints about failings of imaging that occurred between 2013 and 2020, most of which concluded after 2018. These fell into four main categories: failure to follow national guidelines on reporting unexpected imaging findings, failure to act on important unexpected findings, delays in reporting imaging findings, and failure to learn from past mistakes.

The report highlighted effects on patients and families. For example, signs of cancer in $x$ ray pictures and scans were not reported in several cases, leading to delayed diagnosis and poorer outcomes. In one case, an 18 month delay in a diagnosis of pancreatic cancer meant a patient missed out on earlier treatment that could have prolonged their life. By the time another patient was told their cancer was terminal it was too late for them to get their affairs in order and see their son before they died.

The report emphasised that the failings were not limited to radiologists, radiographers, or imaging services but related to the whole system, including primary and secondary care, with "significant implications for all clinical professionals ... responsible for requesting imaging and acting on its findings."

Peter Walsh of the charity Action against Medical Accidents said, "We see in our own work how vital diagnostic services are and the awful effect on people's lives when they go wrong. There have now been a raft of reports and recommendations about improving radiology services.

"This is a major patient safety issue, and we need to see the various recommendations implemented as a matter of urgency."
Michelle Mitchell, Cancer Research UK’s chief executive, said, "With imaging services severely stretched, making sure there is enough staff should be a top priority. And investment in IT systems and innovation could help to ensure patients don't get missed or fall through the gaps.”

The report recommended that digital infrastructure be treated as a patient safety issue to be dealt with by the Department of Health and Social Care and NHS England and NHS Improvement, working with NHS $\mathrm{X}$ and NHS Digital.

The department and NHS England and NHS Improvement should provide national guidance on the roles and responsibilities of clinicians, and expected timeframes for each stage of the imaging journey, and should report to MPs on progress by March 2022, it added.

Radiology services funded by the NHS should provide allocated time to staff for meaningful learning and reflection, it added, and clinical directors and senior managers should regularly share the learning from across their departments. The Royal College of Radiologists should review existing guidance on reporting unexpected findings and peer review of radiological reports, the report said.

NHS England and NHS Improvement was approached for comment but had not responded by the time of publication.

\section{Parliamentary and Health Service Ombudsman. Unlocking solutions in imaging: working together to learn from failings in the NHS. 8 Jul 2021. https://www.ombudsman.org.uk/publications/unlocking-solutions-imaging- working-together-learn-failings-nhs,}

This article is made freely available for use in accordance with BMJ's website terms and conditions for the duration of the covid-19 pandemic or until otherwise determined by BMJ. You may use, download and print the article for any lawful, non-commercial purpose (including text and data mining) provided that all copyright notices and trade marks are retained. 